\title{
Digital Simulation of Limit Cycle in Second and Higher Order Analog Filter using MATLAB
}

\author{
Vaibhav Jain \\ (ABES Engg. \\ College,Ghaziabad)
}

\author{
Deepak Garg,Ph.D \\ (ABES Engg. \\ College,Ghaziabad)
}

\author{
A.K. Arora \\ (ABES Engg. \\ College,Ghaziabad)
}

\author{
EC Department, Mahamaya Technical University \\ Noida, U.P
}

\begin{abstract}
The non-linearities like saturation, dead zone and relay etc. of electronic components like op-amp leads to limit cycles in the electronic system. Limit cycles describe the oscillations of nonlinear electronic systems. This paper examines the development of a graphical technique, leading to the use of computer graphics, for systematic analysis of limit cycles in Second and Higher Order Electronic Filter Systems. Its accuracy has been sustained by comparing with the results from digital simulation.
\end{abstract}

Keywords - Phasor Diagram, Limit Cycles, Electronic Filter System

\section{INTRODUCTION}

If the demand for a digital system is heavy, the most effective approach to design is through VLSI implementation. The VLSI implementation of filters can become cost effective if the number of distinct chips needed is kept low, since, then a high demand can be created for each chip. An electronic filter is a frequency selective electronic circuit that passes signals of specified band of frequencies and attenuates the signal of frequencies outside the band. Electronic filters are used in circuits, which require the separation of communication signals according to their frequencies. Electronic filters are widely used in, signal processing and in one form or another in almost all sophisticated electronic instruments. The VLSI implementation of electronic filters composed of passive components, active components, crystals, independent sources etc. The electronic filters can be classified into many configurations but mainly are of two types analog and digital. Electronic filters are classified according to their frequency domain behavior, which was specified in terms of their magnitude and phase response. The most commonly used classification for filters based on frequency domain is:
(i) Low Pass
(ii) High Pass
(iii) Band Pass
(iv) Band Reject

\section{INTRODUCTION TO LIMIT CYCLE}

The limit cycles describe the oscillations of nonlinear electronic system. The existence of a limit cycle corresponds to an oscillation of fixed amplitude and period. The limit cycle problem is an important issue that is needed to be solved when dealing with filters. The problem of limiting cycle results in marginal stability. The main reason to rely on the relatively completely stable dynamics is that, it often seems exceedingly difficult to control and practically exploit behaviours such as limit cycles. It is important to note that a limit cycle, in general is an undesirable characteristic of an electronic circuits. It may be tolerated only if its amplitude is within specified limits.
Determination of existence of limit cycles is not an easy task as these may depend upon both type and amplitude of the input signal. Prediction of limit cycles is very important because limit cycles can occur in any kind of system. The constant oscillation associated with the limit cycles can cause deteriorating performance or even failure of the system hardware. A graphical technique, suitable for computer graphics, has been developed for prediction of a limit cycle. The method is derived from the basic concept of phasor relationships between the system variables.

\section{MATHEMATICAL MODEL}

The block diagram of a general $2 \times 2$, two dimensional system Patra K.C. (1993), Nikiforuk. P.N. (1968) consists of two electronic filter subsystems $S_{1}$ and $S_{2}$. Each subsystem contains a non-linearity like saturation, dead zone etc. and a stable or neutral part i.e. electronic filter like LPF, HPF etc. connected in series. This is a most general structure representation of twodimensional system Patra. K.C. (1994). The complete two dimensional structure system is shown in Fig:1.

Where

C : Amplitude of sub-system output

$\mathrm{R} \quad$ : Input Amplitude to the subsystem from the other

$\mathrm{N}(\mathrm{X})=\mathrm{Y} / \mathrm{X} \quad$ :Describing Function of the non-linear elements

$\mathrm{X} \quad$ : Amplitude of input to non-linear element

Y : Amplitude of non-linear element output

(Approximated by fundamental component)

$\theta_{\mathrm{e}} \quad:$ Phase shift of the subsystem closed loop response

$\theta_{1} \quad:$ Phase shift of the subsystem closed loop response

$\omega \quad$ : Angular Frequency in $\mathrm{rad} / \mathrm{second}$

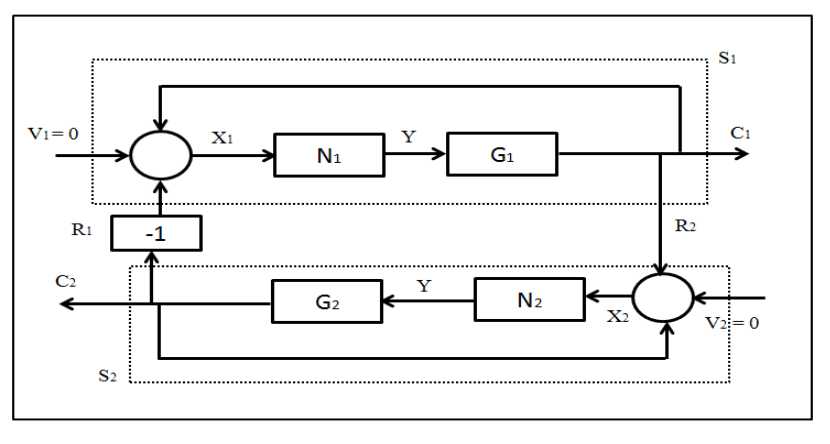

Fig: 1 General 2 × Electronic Fiter System

The phasor diagram for the general 2x2 Electronic Filter system in autonomous state is shown in Fig:4.2. For a fixed frequency ' $\omega$ ', the angles $\theta_{\mathrm{L} 1}$ and $\theta_{\mathrm{L} 2}$ are fixed. 




Fig: 2 Phasor Diagram of 2 x 2 Electronic Filter System

The sides of the triangle $\mathrm{OBD}_{2}$ correspond to subsystem 1 . For a given amplitude $\mathrm{R}_{1}$, the sides $\mathrm{OB}$ subtend a constant angle $\theta^{\prime}=180^{\circ}-\theta_{\mathrm{L} 1}$ constraining the points $\mathrm{O}, \mathrm{B}$ and $\mathrm{D}_{2}$ to lie in a circle as shown in Fig. 2. Thus, for a given $R_{1}$ and $\omega$, the output $\mathrm{C}_{1}$ will be given by the side $\mathrm{OD}_{2}$ if the conditions mentioned below are satisfied simultaneously:

i) The Point $\mathrm{D}_{2}$ must lie on the segments ODB of circle subtending an angle $180^{\circ}-\theta_{\mathrm{L} 1}$.

ii) $\mathrm{OD}_{2}=\mathrm{Y}_{1} \mathrm{G}_{1}, \mathrm{BD}_{2}=\mathrm{X}_{1}$, where the relation between $\mathrm{X}_{1}$ and $\mathrm{Y}_{1}$ is the Describing Function of non-linear element and $G_{1}$ is a known function of $\omega$.

Similar arguments hold good for the triangle $\mathrm{OAD}_{1}$ representing parameters of the subsystem 2 .

For the system limit cycling in the autonomous state, it can be expressed by inspecting of Fig: 4.1 that

$$
\mathrm{C}_{1}=\mathrm{R}_{2} \text { and } \mathrm{R}_{1}=-\mathrm{C}_{2}
$$

Both the triangles are superimposed in a fashion shown in Fig: 2 to satisfy the condition stated above. Once triangle $\mathrm{OD}_{2} \mathrm{~B}$ and circle through points $\mathrm{O}, \mathrm{D}$ and $\mathrm{B}$ are determined, then for a particular $\mathrm{R}_{1}$ and $\omega, \mathrm{OA}$ is drawn opposite to $\mathrm{OB}$ and $\mathrm{AD}_{2}$ represent the phasor $X_{2}$ drawn at an angle $\theta_{\mathrm{L} 2}$ with phasor $\mathrm{C}_{2}$. The intersection of this straight line $\mathrm{AD}_{\mathrm{i}}$ (representing $\mathrm{X}_{2}$ ) with the circle, as shown in Fig: 4.2, would represent possible self oscillation if the conditions mentioned below are satisfied:

i) The Point $\mathrm{D}_{\mathrm{i}}(\mathrm{i}=1,2$ implying double interaction) lies on the intersection of segment $\mathrm{OD}_{\mathrm{i}} \mathrm{B}$ of a circle subtending an angle $\left(180^{\circ}-\theta_{\mathrm{L} 1}\right)$ on $\mathrm{OB}$ and a straight line ADi making an angle $\theta_{\mathrm{L} 2}$ with $\mathrm{OA}$.

ii) $\quad \mathrm{OD}_{\mathrm{i}}=\mathrm{C}_{1}=\mathrm{Y}_{1} \mathrm{G}_{\mathrm{i}} ; \mathrm{i}=1,2 \quad \mathrm{BD}_{\mathrm{i}}=\mathrm{X}_{1}$, where $\mathrm{Y}_{1}=$ $\mathrm{N}_{1} \mathrm{X}_{1}$

iii) $\mathrm{OA}=\mathrm{C}_{2}=\mathrm{Y}_{2} \mathrm{G}_{2}$ and $\mathrm{AD}_{\mathrm{i}}=\mathrm{X}_{2}$, where $\mathrm{Y}_{2}=\mathrm{N}_{2} \mathrm{X}_{2}$

\section{NORMALIZED PHASOR DIAGRAM}

For various possible values of $\mathrm{R}_{1}$, it is necessary to construct separate phasor diagrams to check the above conditions for a fixed frequency. If all these quantities are normalized with respect to R1, a single phasor diagram (for a particular value of frequency) can be used for checking possibility of limit cycle. This diagram is termed as normalized phasor diagram and hence the name of the technique, is shown in Fig:3.

From the diagram we can drive:

$$
O A=\frac{C_{2}}{R_{1}}=-1.0
$$

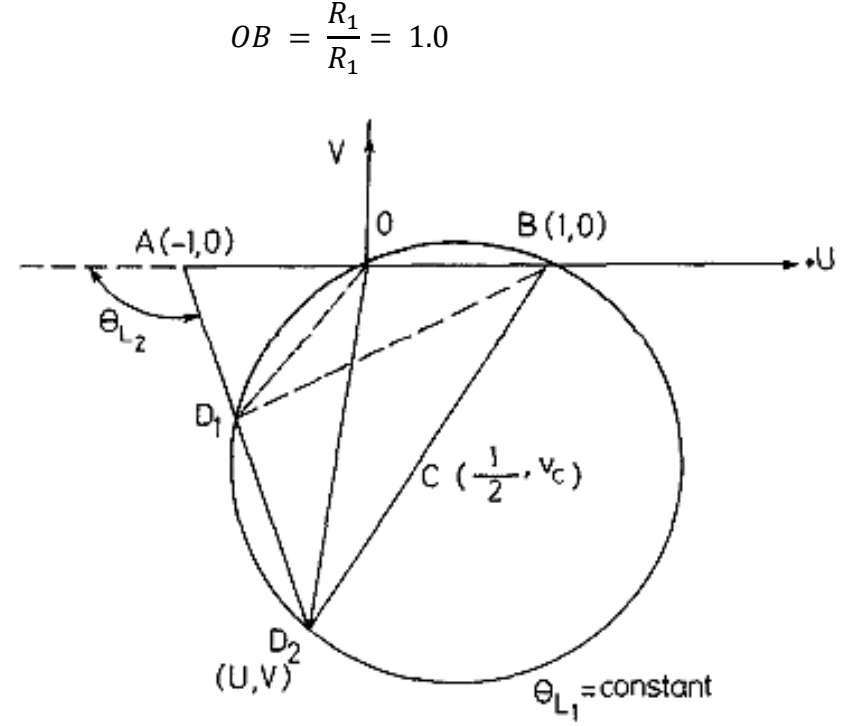

Fig: 3 Normalized Phasor Diagram for second order 2 x 2 Electronic Filter System

$$
\begin{aligned}
& O D_{i}=\frac{C_{1}}{R_{1}}=\frac{C_{1}}{C_{2}}, \quad i=1 \text { or } 2 \\
& B D_{i}=\frac{X_{1}}{R_{1}} \\
& A D_{i}=\frac{X_{2}}{R_{1}}
\end{aligned}
$$

In Fig: 3, C is the center of circle $\mathrm{OBD}_{i}$ of radius $r$ $=\mathrm{OC}$. Selecting $\mathrm{O}$ as the origin in Fig: 4.3, the co-ordinates of the points $D_{i}$ can be determined.

From triangle $\mathrm{D}_{\mathrm{i}} \mathrm{CO}$,

The co-ordinates of the point $C$ are $\left(0.5,-0.5 / \tan \theta_{\mathrm{L} 1}\right)$.

The radius of the circle $\mathrm{OC}=0.5 / \sin \theta_{\mathrm{L}}$

The equation of the straight line $\mathrm{AD}_{\mathrm{i}}$ is obtained as:

$\mathrm{U}=\mathrm{v} \cot \theta_{\mathrm{L} 2}-1$

The co-ordinates of the intersection points, $\mathrm{D}_{\mathrm{i}}$ of the circle and straight line $\mathrm{AD}_{\mathrm{i}}$ are obtained as:

$$
v_{i}=\frac{3 \cot \theta_{\mathrm{L} 2}+\cot \theta_{\mathrm{L} 1}+\sqrt{\left(3 \cot \theta_{\mathrm{L} 2}+\cot \theta_{\mathrm{L} 1}\right)^{2}-8 \operatorname{cosec}^{2} \theta_{\mathrm{L} 1}}}{2 \operatorname{cosec}^{2} \theta_{\mathrm{L} 2}}
$$$$
\mathrm{u}_{\mathrm{i}}=\mathrm{v}_{\mathrm{i}} / \tan \theta_{\mathrm{L} 2}-1
$$

It may be noted that co-ordinates of the point $D_{i}$ are the functions of angle $\theta_{\mathrm{L} 1}, \theta_{\mathrm{L} 2}$ and later are function of frequency. Hence, for specific frequency, if the co-ordinates are known of $\mathrm{D}_{\mathrm{i}}$, the other variables $\left(\mathrm{X}_{1}, \mathrm{X}_{2}\right.$ or $\left.\mathrm{C}_{1}, \mathrm{C}_{2}\right)$ can be determined as:

$$
\begin{aligned}
& O D_{i}=\left(u_{i}^{2}+v_{i}^{2}\right)^{2} \\
& O A=-1.0 \\
& B D_{i}=\left[\left(1-u_{i}\right)^{2}+v_{i}^{2}\right]^{0.5} \\
& A D_{i}=\left[\left(1+u_{i}\right)^{2}+v_{i}^{2}\right]^{0.5} \\
& \mathrm{~N}_{1}\left(\mathrm{X}_{1}\right)=\mathrm{Y}_{1} / \mathrm{X}_{1}=\mathrm{C}_{1} /\left(\mathrm{G}_{1} \mathrm{X}_{1}\right)=\mathrm{OD}_{\mathrm{i}} /\left(\mathrm{G}_{1} \mathrm{BD}_{\mathrm{i}}\right)
\end{aligned}
$$




$$
\begin{aligned}
& \mathrm{N}_{2}\left(\mathrm{X}_{2}\right)=\mathrm{Y}_{2} / \mathrm{X}_{2}=\mathrm{C}_{2} /\left(\mathrm{G}_{2} \mathrm{X}_{2}\right)=\mathrm{OA} /\left(\mathrm{G}_{2} \mathrm{AD}_{\mathrm{i}}\right) \\
& \mathrm{X}_{1} / \mathrm{X}_{2}=\mathrm{BD}_{\mathrm{i}} / \mathrm{AD}_{\mathrm{i}}
\end{aligned}
$$

Corresponding to the value of $\mathrm{N}_{1}$ and $\mathrm{N}_{2}$ determined from equation (4.5) and (4.6), the value of $X_{1}$ and $X_{2}$ can be found out from the describing function expressions of both nonlinearities. The ratio of $\mathrm{X}_{1} / \mathrm{X}_{2}$ is again obtained from the equation (4.7). This process is repeated for different values of ' $\omega$ '. The value of $X_{1} / X_{2}$ calculated from various ' $\omega$ ' are tabulated and a graph is plotted between these two parameters. The ratio $\mathrm{X}_{1} / \mathrm{X}_{2}$ calculated from Equations (4.5 and 4.6) and (4.7) intersect at a point, this intersection point gave the frequency of the limit cycle. Once this limit cycle frequency is determined, the amplitude of other variables of interest can be determined.

\section{IMPLEMENTATION}

For the system shown in Fig: 1, the circuit element is LPF whose transfer function, $\mathrm{G}_{1}(\mathrm{~s})=1.586 /\left(\mathrm{s}^{2}+1.414 \mathrm{~s}+1\right)$ and high Pass Filter with transfer function, $\mathrm{G}_{2}(\mathrm{~s})=1.586 \mathrm{~s}^{2} /\left(\mathrm{s}^{2}+\right.$ $1.414 \mathrm{~s}+1)$. The non-linearity $\mathrm{N} 1$ and $\mathrm{N} 2$ both are saturation. The frequency ' $\omega$ ' has been varied from 0.4 to 0.7 and the ratio $\mathrm{X}_{1} / \mathrm{X}_{2}$ are computed from equation $(5 \& 6)$ and equation (7). The results of computation are tabulated in Table 1.

\begin{tabular}{|c|c|c|c|c|}
\hline $\begin{array}{c}\text { Frequency } \\
\text { ' } \omega \text { ' }\end{array}$ & $\theta_{\mathrm{L} 1}$ & $\theta_{\mathrm{L} 2}$ & $\begin{array}{r}X_{1} / X_{2} \\
\text { from eq. } \\
(5 \& 6)\end{array}$ & $\begin{array}{c}\mathrm{X}_{1} / \mathrm{X}_{2} \\
\text { from eq. } \\
(7)\end{array}$ \\
\hline 0.4 & -33.96 & -33.96 & 1.0754 & 1.256 \\
\hline 0.45 & -38.45 & -38.45 & 1.0596 & 1.157 \\
\hline 0.5 & -43.32 & -43.32 & 1.0353 & 1.098 \\
\hline 0.55 & -47.67 & -47.67 & 1.0223 & 1.046 \\
\hline 0.6 & -52.98 & -52.98 & 0.9985 & 1.020 \\
\hline 0.65 & -57.97 & - 57.97 & 0.9852 & 0.9675 \\
\hline 0.7 & -62.74 & -62.74 & 0.9723 & 0.9223 \\
\hline
\end{tabular}

Table: 1 Results of Computation

The calculated values of ratio $\mathrm{X}_{1} / \mathrm{X}_{2}$ from equation ( $5 \& 6$ ) and equation (7) tabulated in Table 1 are plotted with respect to ' $\omega$ '. From the graph the intersection point of both the lines is determined, which gives the frequency of limit cycle. The plot is as shown in Fig: 4.

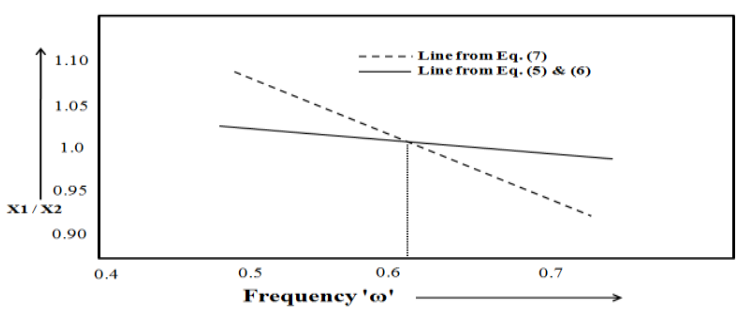

Fig: 4 Plot of $X_{1} / X_{2}$ with respect to ' $\omega$ '

From the graph, the frequency of limit cycle is found to be $0.6183 \mathrm{rad} / \mathrm{sec}$. The amplitude of limit cycle is calculated as $\mathrm{C}_{1}$ $=0.5835, \mathrm{C}_{2}=0.3185$ from Equation $(5 \& 6)$.

The detailed results using the above Graphical Method are tabulated in Table 2.

\begin{tabular}{|c|c|c|c|c|c|c|}
\hline \multicolumn{2}{|c|}{$\begin{array}{c}\text { System } \\
\text { (Filter Type) }\end{array}$} & \multicolumn{2}{|c|}{ Name of Non-Linearity } & \multicolumn{3}{|c|}{$\begin{array}{c}\text { Graphical Method } \\
\text { Results }\end{array}$} \\
\hline $\mathbf{G}_{\mathbf{1}}$ & $\mathbf{G}_{\mathbf{2}}$ & $\mathbf{N}_{\mathbf{1}}$ & $\mathbf{N}_{\mathbf{2}}$ & $\boldsymbol{\omega}$ & $\mathbf{C}_{\mathbf{1}}$ & $\mathbf{C}_{\mathbf{2}}$ \\
\hline LPF & HPF & Saturation & Saturation & $\begin{array}{c}0.618 \\
3\end{array}$ & $\begin{array}{c}0.583 \\
5\end{array}$ & $\begin{array}{c}0.318 \\
5\end{array}$ \\
\hline $\begin{array}{c}\text { LPF } \\
\text { (III } \\
\text { order) }\end{array}$ & $\begin{array}{c}\text { HPF } \\
\text { (III } \\
\text { order) }\end{array}$ & Saturation & Saturation & $\begin{array}{c}0.513 \\
5\end{array}$ & $\begin{array}{c}0.622 \\
9\end{array}$ & $\begin{array}{c}0.257 \\
8\end{array}$ \\
\hline
\end{tabular}

Table: 2 Results of Graphical Method

\section{IMPLEMENTATION USING MATLAB}

The MATLAB 7.0 version is used as the simulation software for simulating the system. The SIMULINK block diagram consists of some major components which are as follows:

The major components of the SIMULINK model are:

(i) Sub-system1 and sub-system2 containing the linear time invariant continuous part and non-linear time invariant parts.

(ii) $\mathrm{A}$ signal generator for giving initial excitation signal

(iii) Scope to view the wave form.

The SIMULINK model is simulated to obtain the time history plots shown in Fig:5 to Fig:8. From the time history plot frequency and amplitude of the limit cycles for a particular Electronic system is computed.

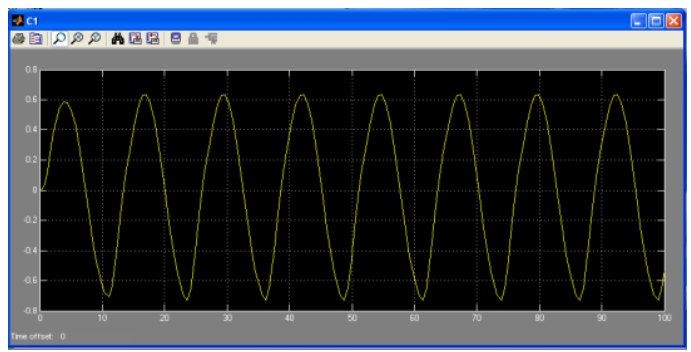

Fig: 5 Output C1 of LPF with Saturation Non-Linearity

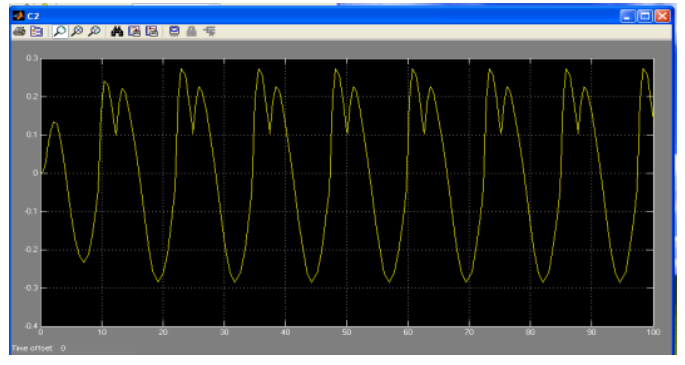

Fig: 6 Output C2 of HPF with Saturation Non-Linearity



Fig: 7 Output C9 of III order LPF with Saturation NonLinearity 


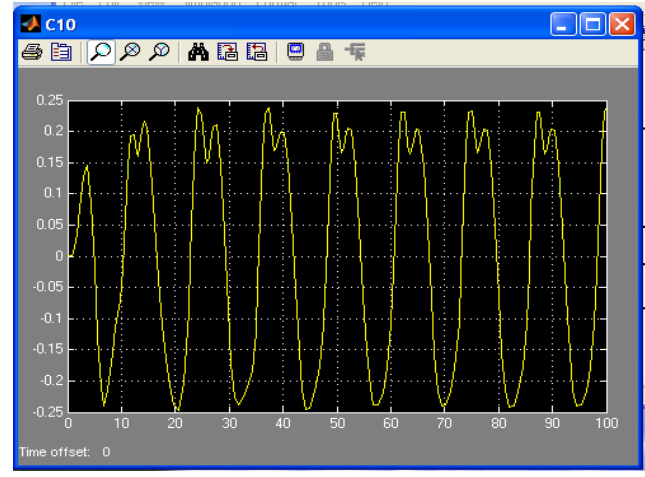

Fig: 8 Output C10 of III order HPF with Saturation NonLinearity

From the time history plots shown in Fig: $5-8$ frequency and amplitude of the Limit cycles for different electronic filter system are compared which is as shown in Table-3.

Table: 3 MATLAB / SIMULINK Results

\begin{tabular}{|c|c|c|c|c|c|c|}
\hline \multicolumn{2}{|c|}{$\begin{array}{c}\text { System } \\
\text { (Filter Type) }\end{array}$} & \multicolumn{2}{|c|}{ Name of Non-Linearity } & \multicolumn{3}{|c|}{$\begin{array}{c}\text { MATLAB / SIMULINK } \\
\text { Results }\end{array}$} \\
\hline $\mathbf{G}_{\mathbf{1}}$ & $\mathbf{G}_{\mathbf{2}}$ & $\mathbf{N}_{\mathbf{1}}$ & $\mathbf{N}_{\mathbf{2}}$ & $\boldsymbol{\omega}$ & $\mathbf{C}_{\mathbf{1}}$ & $\mathbf{C}_{\mathbf{2}}$ \\
\hline LPF & HPF & Saturation & Saturation & 0.5969 & 0.5778 & 0.3125 \\
\hline $\begin{array}{c}\text { LPF } \\
\text { (III } \\
\text { order) }\end{array}$ & $\begin{array}{c}\text { HPF } \\
\text { (III } \\
\text { order) }\end{array}$ & Saturation & Saturation & 0.5235 & 0.6429 & 0.2378 \\
\hline
\end{tabular}

\section{CONCLUSION}

A graphical method leading to the use of computer graphics has been developed. It provides a useful insight into the nature of a limit cycle in such a system. The method is particularly elegant for systems incorporating relays with ideal two state characteristics. The technique can also be extended for the analysis of complex oscillations during the process of signal stabilization.

The use of SIMULINK for oscillation prediction provides an ideal tool for comparing the accuracy of DF solutions for more complicated system.

\section{REFERENCES}

[1] A.S. Sedra and Kenneth C. Smith, 1998, Microelectronic Circuits, Oxford University.

[2] Anna Domanska, 2001. Dither method for linearization of static characteristics of a class of converters. Poznan University of Technology, Polanka3, Poland.

[3] Anthony Chan Carusone and David A.Johns, 2002. Analog Filter Adaptation using A Dithered linear search Algorithm. 0-7803-7448-7/02 IEEE.

[4] B.W. Bomar, 1989. On the design of second order state space digital filter sections, IEEE Trans. On Circuit and System, vol.CAS-36, pp.542.552.

[5] B.W. Bomar, 1985. New second order state space structures for realizing low round off noise digital filters, IEEE Trans.Acoust., Speech, Signal Procee, vol. ASSP33, pp.106-110.

[6] K.C. Patra and Y.P. Singh, 1996. Graphical Method of Prediction of limit cycle for multivariable nonlinear systems, IEEE Proc.-Control Theory Appl., vol.143, No.5, pp.423-428.

[7] Malekzadeh, F.A.; Mahmoudi, R.; Van Roermund, A.H.M., 2009. A new statistical approach for nonlinear analysis of limit cycle amplifiers, Radio and Wireless Symposium, 2009, RWS'09 IEEE 18-22, pp.47-50.

[8] M.D. Macro, M.Forti and Alberto Tesi, 2002. Existence and Characterization of Limit Cycles in Nearly Symmetric Neural Networks, IEEE Trans. On Circuit and systems, vol.49, No.7, pp.979-992.

[9] M.E. Ahmed and P.R. Belanger, 1984. Limit Cycles in fixed-point implementation of control algorithms, IEEE Trans.Ind.Electron., vol.IE-31,pp.235-242.

[10] Singh Y.P., and Subramanian,S., 1980. Frequency response identification of structure of non-linear systems," IEEE Proc. 1980, 127 pp 77-82. 